\title{
Design and Development of Submerged Arc Welding Acidic Flux
}

\author{
Aditya Kumar \\ Department of Mechanical Engineering, NSUT, Sector-3, Dwarka, New Delhi-110078, India \\ Corresponding Author :aditya_rathihere@yahoo.com
}

\begin{abstract}
An acidic flux was intended and developed with the variation of some flux constituents. The basicity index of the flux was kept as 1.84. It was designed to weld the mild steel plates on submerged arc welding machine. A study was done with developed flux on two-level factorial design. Voltage and current were the controlled parameters along with feed rate, nozzle distance and creep feed as uncontrolled parameters selected for experimentation. Eight experiments were performed. Weld bead width and Hardness were the responses measured. Design expert software was used the do the analysis. Finally, it can be determined that travel speed was the most momentous factor for the hardness and weld bead dimensions of the joint.
\end{abstract}

Keywords: Flux basicity index; Ball mill; Vickers hardness; Weld dimensions.

\section{INTRODUCTION}

Since 1930s a wide variety of fluxes has been developed. Flux preparation is a time-consuming process, different techniques were used to design the flux. Basicity index was kept in mind while designing the flux. Some of the investigator recommended that titanium is a deoxidizer along with manganese; it will minimize the oxygen content. The consequence of the study illustrate that the oxygen level of the developed flux was well below than other fluxes (W.J. Lewis et.al,1961). Welding flux plays a vital and complex role in the welding processes.

Fluxes must melt in weld pool at appropriate temperature, must have a density less than the weld deposit. Welding consumables affect the weld deposit chemically and physically (Butler et.al, 1961). The dissolved oxygen-content is beneficial for the impact strength and transition temperature of the welded joint (Palm et.al,1972). The effect of submerged arc welding limitations along with flux basicity index on the weld interaction was studied and finally settled for directing the weld-metal configuration. The results showed that welding current and voltage are influencing the weld composition (Panday et.al, 1994). The study carried out on influence of chemical structure, micro construction and stretchable properties of SAW on AISI 1020 steel was agreed out, the result displays that acicular ferrite was existing in the flux with contents of $\mathrm{TiO}_{2}$ (Paniagua et.al, 2005). The study carried out on flux mixture and welding parameters for low carbon steel plates shows that flux composition has individual as well and mix effects on responses (Kanji lal et.al,2006). In a twin wire joining process current, voltage, wire thicknesses and polarity are the major issues influencing the flux ingesting (Sharma et.al,2008). voltage and welding speed both will reduce the diffusion in submerged arc welding as suggested by (Vinod et.al,2011). Cost of welding flux is nearly half as compared to other constituents in SAW process. Development of better welding flux in terms of mechanical properties and efficiency, that is cost operative too, was the focus of many scholars (Gautam et.al, 2017). $\mathrm{MnO}, \mathrm{MgO}, \mathrm{NiO}$ in a CaO- $\mathrm{SiO}_{2}-\mathrm{Al}_{2} \mathrm{O}_{3}$ arrangement of flux has higher solidity in comparison to $\mathrm{Fe}-\mathrm{Cr} \mathrm{CaO}$ based fluxes (Ajay Kumar et.al, 2012). 


\section{FLUX PREPARATION}

All the flux constituents were mixed in a ball Mill as shown in Figure 1(a). It consists of number of steel balls, 10 $\mathrm{mm}$ in diameter. When the ball Mill rotate at high speed, all the flux constituents start mixing with each other. The flux should be a homogeneous mixture of all the constituents, when steel balls fall on the particles under gravity that makes it as homogeneous. Ball mill should be operated at 60 to $75 \%$ of its critical speed for effective operation. Attachment of ball mill is shown in Figure 1(b).

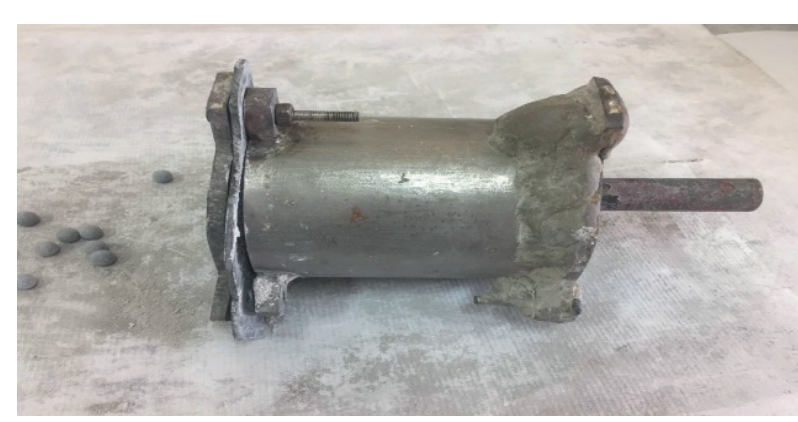

Fig 1. (a) Ball Mill

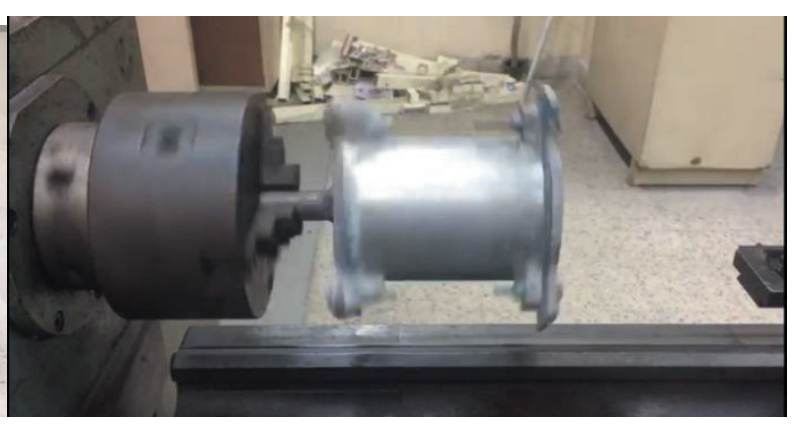

(b) Ball Mill Setup

Table 1 shows water and binder composition used for the preparation of the flux. Composition with weight percentage of different components used for making the fluxes is given in Table 2. Total $(940 \mathrm{~g})$ powdered chemicals was used. Binder (potassium silicate) and hot water approximately $(360+630 \mathrm{ml})$ respectively was then sprayed on the mixture. The whole mixture was then mixed with hands to form the small granules. When it became granular then the mixing progression was at a standstill. Flux was aloof and spread on flat piece of paper for $48 \mathrm{hrs}$. The dried flux was parched in a muffle kiln for $2 \mathrm{hrs}$ at $600^{\circ} \mathrm{C}$. It was then permitted to cool down at room environment. Figure 2(a) and Figure 2(b) shows that how to mix the flux constituents manually. The muffle furnace used for baking of the flux is shown in Figure 2(c)

Table 1. Binder and Water composition

\begin{tabular}{|c|c|c|c|}
\hline S No. & Type of Flux & Water & $\begin{array}{c}\text { Binder (Potassium } \\
\text { silicate) }\end{array}$ \\
\hline 1. & Acidic & 0.4 & 0.5 \\
\hline
\end{tabular}

Table 2. Flux constituent's compositions

\begin{tabular}{|c|c|c|c|c|c|c|c|}
\hline S No. & Type of Flux & \multicolumn{5}{|c|}{ Acidic flux constituent's compositions (Weight Percentage) } & \multirow{2}{*}{ Basicity Index } \\
\hline & & $\mathrm{Al}_{2} \mathrm{O}_{3}$ & $\mathrm{CaCO}_{3}$ & $\mathrm{MgO}$ & $\mathrm{TiO}_{2}$ & $\mathrm{NiO}$ & \\
\hline 1. & Acidic & 44.0 & 22 & 25 & 7 & - & 1.84 \\
\hline
\end{tabular}



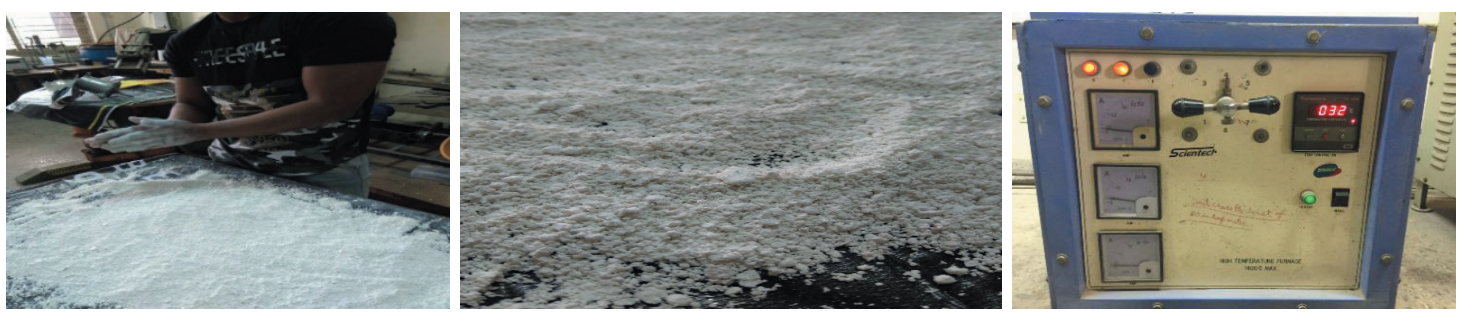

Figure 2. (a) Constituents Mixing (b) Granular Flux (c) Electric Furnace

\section{CALCULATION OF BASICITY INDEX}

Categorization of submerged arc welding fluxes can be on the basis of the basicity index, (B.I) It is the proportion of amount of basic oxides to acidic oxides. The formula used for calculation is shown as:

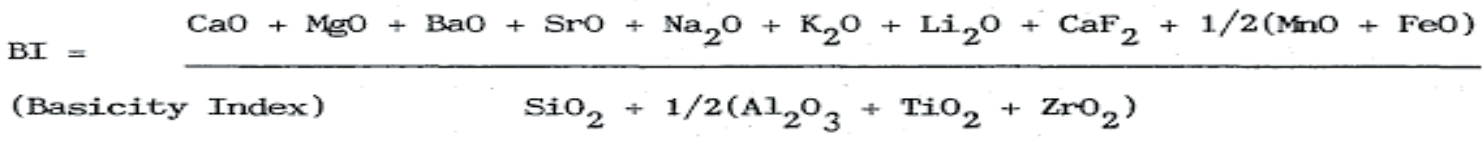

Acidic fluxes have different applications then basic fluxes these are preferred for single-pass welding. In calculation, acidic flux usually has additional resistance to basic fluxes to plate contamination by grease and corrosion.

\section{DESIGN METHOD}

In this design process, factorial designs were used because in this process each level of independent variable with each level of others to give all possible combination. These plans are often used as initial point for very intricate response surface modelling also. In this effort $2^{2}$ plan was used.

\section{WELDING TECHNIQUE}

In this research work, bead on plates as revealed in Figure 4 were produced by using semi-automatic submerged arc welding method as per the design matrix shown in Table 8. The copper coated electrode of $3.15 \mathrm{~mm}$ diameter was used. Mild steel plates were used to make the bead on plates arrangement with fixed welding parameters as shown in Table 3. On the basis of weld appearance, good slag detachability, arc initiation, and arc stability the fixed welding parameters were selected. Each pass of weld was preceded by thorough cleaning and removal of slag form the joint. In this way, total eight plates were welded. Four are revealed in Figure 3. The two manageable features were welding voltage and travel speed. The first issue welding voltage was ranged between 40-60 Volt. Other feature trolley travel speed was ranged between 30-70 $\mathrm{cm} / \mathrm{min}$. The Design matrix is produced in design expert software as revealed in Table 8. The matching answers were recorded the result are publicized in Table 6 . The variable parameters are specified in Table 4. The chemical arrangement of welding plate and welding probe is specified in Table 5.

Table 3. Welding Constraints

\begin{tabular}{|c|c|}
\hline Constraints kept fixed & Unit of Limits \\
\hline Trolley travel speed & $6 \mathrm{~cm} / \mathrm{sec}$ \\
\hline Nozzle Distance & $3 \mathrm{~mm}$ \\
\hline Wire Feed rate & $3 \mathrm{~cm} / \mathrm{min}$ \\
\hline
\end{tabular}


Table 4. Limitations Varied

\begin{tabular}{|c|c|c|c|}
\hline Plates & Voltage(V) & Travel Speed(cm/min) & Current(A) \\
\hline I & 40 & 30 & 475 \\
\hline II & 40 & 70 & 450 \\
\hline III & 60 & 30 & 550 \\
\hline IV & 60 & 70 & 471 \\
\hline
\end{tabular}

Table 5. Configuration of Probe and Weld Plates

\begin{tabular}{|c|c|c|c|c|c|c|c|c|c|c|c|}
\hline Configuration & $\mathrm{C}$ & $\mathrm{Mn}$ & $\mathrm{Si}$ & $\mathrm{Ni}$ & $\mathrm{Cr}$ & $\mathrm{S}$ & $\mathrm{P}$ & $\mathrm{Mo}$ & $\mathrm{Cu}$ & $\mathrm{W}$ & $\mathrm{Fe}$ \\
\hline Electrode EL-8 & 0.08 & 0.5 & 0.05 & 0.33 & 0.83 & - & - & - & - & - & \\
\hline Base plate & 0.30 & 0.598 & 0.31 & 0.11 & 0.040 & 0.014 & 0.063 & 0.088 & 0.083 & 0.153 & 98.04 \\
\hline
\end{tabular}
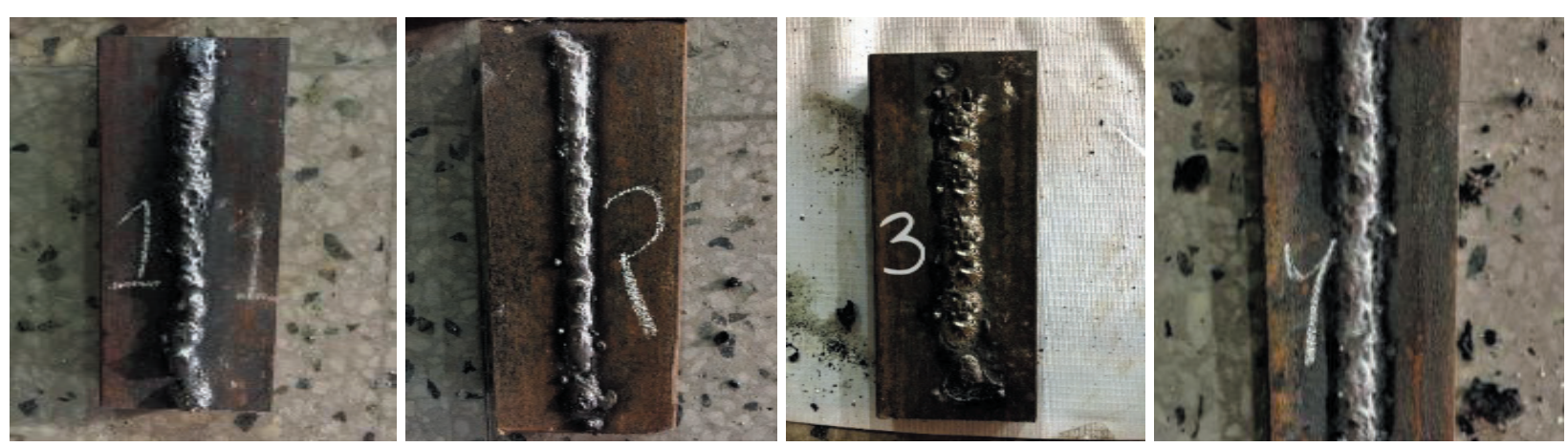

Figure 3. Welded Plates

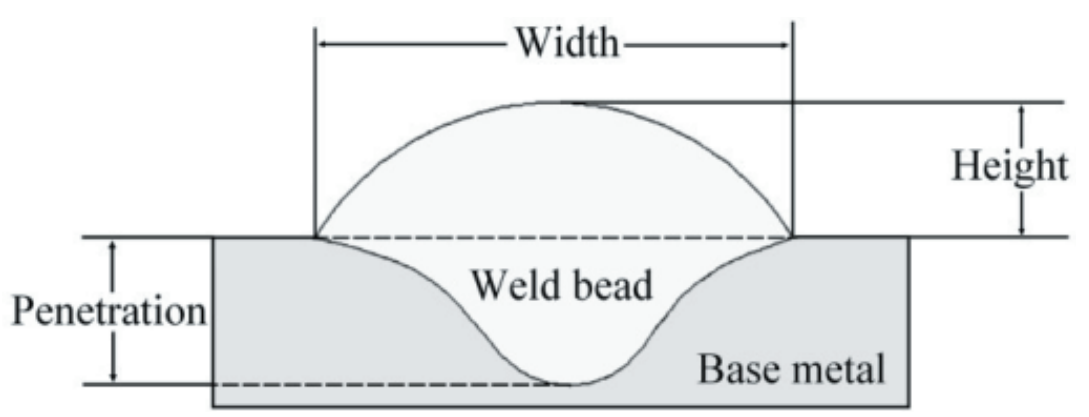

Figure 4. Bead on plate arrangement 


\section{RESPONSE 1: WELD BEAD GEOMETRY}

Weld bead dimensions i.e., height, width and penetration are important physical characteristics of a welded joint, dimensions of the prepared specimen are shown in Table 6.

Table 6. Weld bead dimensions

\begin{tabular}{|c|c|c|c|c|c|}
\hline \multirow{2}{*}{$\begin{array}{c}\text { Type of } \\
\text { Flux }\end{array}$} & \multirow{2}{*}{$\begin{array}{c}\text { Welding } \\
\text { Voltage(V) }\end{array}$} & Trolley speed (cm/min) & \multicolumn{3}{|c|}{ Mean of weld bead dimensions (mm) } \\
\cline { 4 - 6 } & & & Bead Height & Bead Width & Penetration \\
\hline \multirow{3}{*}{ Acidic } & 40 & 30 & 4.2 & 11.8 & 4.4 \\
\cline { 2 - 6 } & 40 & 70 & 2.5 & 12.7 & 3.4 \\
\cline { 2 - 6 } & 60 & 30 & 3.7 & 15.1 & 4.2 \\
\cline { 2 - 6 } & 60 & 70 & 2.2 & 10.6 & 3.5 \\
\hline
\end{tabular}

\section{RESPONSE 2: VICKERS HARDNESS}

Hardness of the weld beads was restrained on VHN Testing machine with diamond indenter by putting $30 \mathrm{kgf}$ weight on the ready specimens $(10 \times 50 \times 20 \mathrm{~mm})$ as shown in Fig 8 and mean of four readings from various samples is revealed in Table 7.

Table 7 Average Hardness value

\begin{tabular}{|c|c|c|c|}
\hline Type of Flux & Welding Voltage(V) & Travel speed (cm/min) & Hardness (VHN)(Mean) \\
\hline \multirow{4}{*}{ Acidic } & 40 & 30 & 182.545 \\
\cline { 2 - 4 } & 40 & 70 & 224.337 \\
\cline { 2 - 4 } & 60 & 30 & 207.630 \\
\cline { 2 - 4 } & 60 & 70 & 234.335 \\
\hline
\end{tabular}

The hardness of base plate was found to be approximately as 132 .
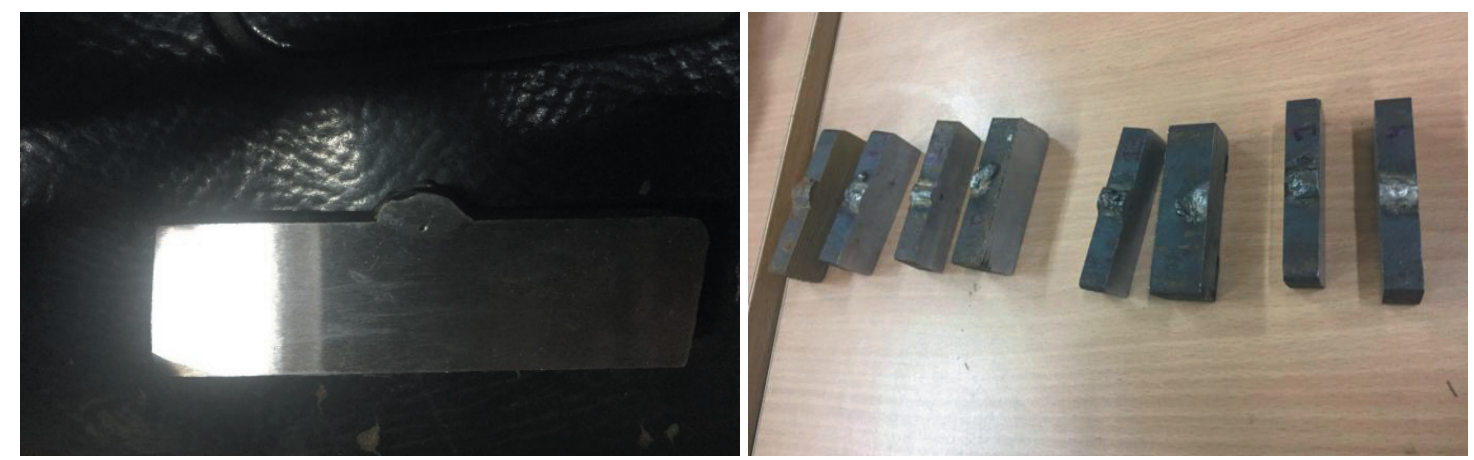

Figure 5. Specimens for Hardness Test 
Table 8. Design Matrix for Acidic flux

\begin{tabular}{|r|r|r|r|r|r|r|r|} 
Std & Run & $\begin{array}{c}\text { Factor 1 } \\
\text { A:Voltage } \\
\text { V }\end{array}$ & $\begin{array}{c}\text { Factor 2 } \\
\text { B:Travel Speed } \\
\text { cm/min }\end{array}$ & $\begin{array}{c}\text { Response 1 } \\
\text { Bead Width } \\
\text { mm }\end{array}$ & $\begin{array}{c}\text { Response 2 } \\
\text { Bead Penetration } \\
\text { mm }\end{array}$ & $\begin{array}{c}\text { Response 3 } \\
\text { Bead Height } \\
\text { mm }\end{array}$ & $\begin{array}{c}\text { Response 4 } \\
\text { Hardness } \\
\text { HV }\end{array}$ \\
\hline 5 & 1 & 40 & 30 & 11.8 & 4.4 & 4.2 & 182.545 \\
\hline 1 & 2 & 40 & 30 & 13 & 3.6 & 4.2 & 181.23 \\
\hline 8 & 3 & 60 & 70 & 10.6 & 3.5 & 2.2 & 238.42 \\
\hline 7 & 4 & 40 & 70 & 13.6 & 3.4 & 2.6 & 224.337 \\
\hline 2 & 5 & 60 & 30 & 15.1 & 4.2 & 3.7 & 207.63 \\
\hline 4 & 6 & 60 & 70 & 11 & 3 & 2.5 & 234.335 \\
\hline 3 & 7 & 40 & 70 & 12.7 & 3.4 & 2.5 & 241.419 \\
\hline 6 & 8 & 60 & 30 & 14.9 & 4 & 3.8 & 198.75 \\
\hline
\end{tabular}

\section{MODELLING OF VICKERS HARDNESS}

The result of (ANOVA) is shown below in Table 9. It shows that the model is significant. The F-value of the model is 27.48 and its p-value is 0.0040 . It in fact shows that model is statistically important at $99 \%$ confidence level. Also, the fit of the model was verified by the coefficient of determination $\mathrm{R}^{2}$. which was found to be 0.9537 , thus directing out that only $4.63 \%$, of the total disparities in the reply was not determined by the study.

Table 9 Hardness

\begin{tabular}{|c|c|c|c|c|c|c|}
\hline Source & Sum of Squares & $\mathbf{d f}$ & Mean Square & F-value & p-value & \\
\hline Model & 4009.01 & 3 & 1336.34 & 27.48 & 0.0040 & significant \\
\hline A & 307.57 & 1 & 307.57 & 6.32 & 0.0657 & \\
\hline B & 3542.97 & 1 & 3542.97 & 72.85 & 0.0010 & \\
\hline AB & 158.47 & 1 & 158.47 & 3.26 & 0.1454 & \\
\hline Pure Error & 194.53 & 4 & 48.63 & & & \\
\hline Cor Total & 4203.54 & 7 & & & & \\
\hline
\end{tabular}

Equations to forecast the behaviour is shown below:

Hardness $=213.58325+6.2005(\mathrm{~A})+21.0445(\mathrm{~B})-.45075(\mathrm{~A} * \mathrm{~B})---(1)$

The normal plan of residuals and plan of actual and forecasted hardness is shown in Figure 6 (a) and (b) respectively. These graph shows that all the points are very near to the straight line means that there is a very small variation in the data. Equation 1 provides the information of hardness of model in the coded form where A is voltage and B is travel speed. 

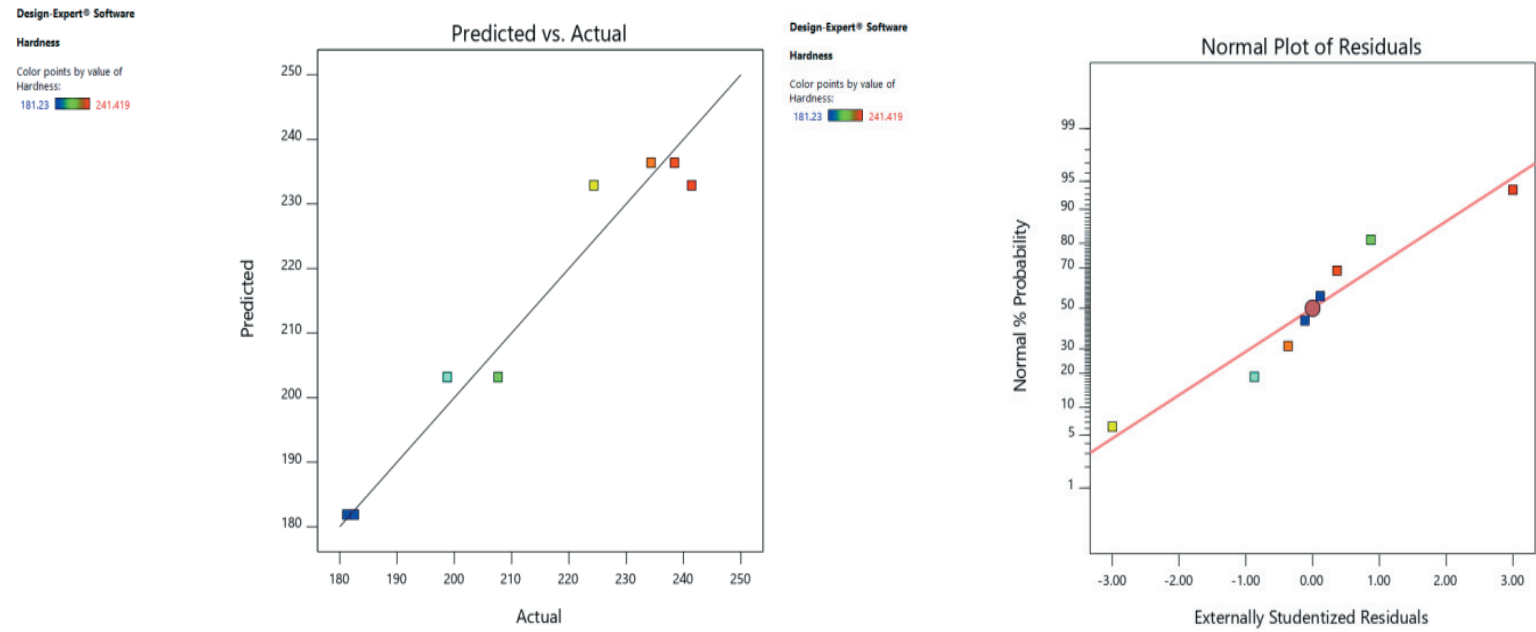

Figure 6. (a) Actual and predicted Hardness (b) Normal plots of residuals

\section{Analysis of Bead Geometry}

ANOVA for Bead width is revealed in Table 10. It shows that the model is significant. The F-value of the model is 19.85 and its p-value is 0.0073 . It in fact predicts that models is statistically important at $99 \%$ confidence level. Also, the acceptance of the model was verified by the quantity of $\mathrm{R}^{2}$ originating to be 0.9370 , thus stating that only $6.30 \%$, of the total change in the result was not determined by the model.

Table 10 Response 2: Bead Width

\begin{tabular}{|c|c|c|c|c|c|c|}
\hline Source & Sum of Squares & df & Mean Square & F-value & p-value & \\
\hline Model & 18.23 & 3 & 6.08 & 19.85 & 0.0073 & significant \\
\hline A & 0.0312 & 1 & 0.0312 & 0.1020 & 0.7654 & \\
\hline B & 5.95 & 1 & 5.95 & 19.43 & 0.0116 & \\
\hline AB & 12.25 & 1 & 12.25 & 40.00 & 0.0032 & \\
\hline Pure Error & 1.23 & 4 & 0.3063 & & & \\
\hline Cor Total & 19.46 & 7 & & & & \\
\hline
\end{tabular}



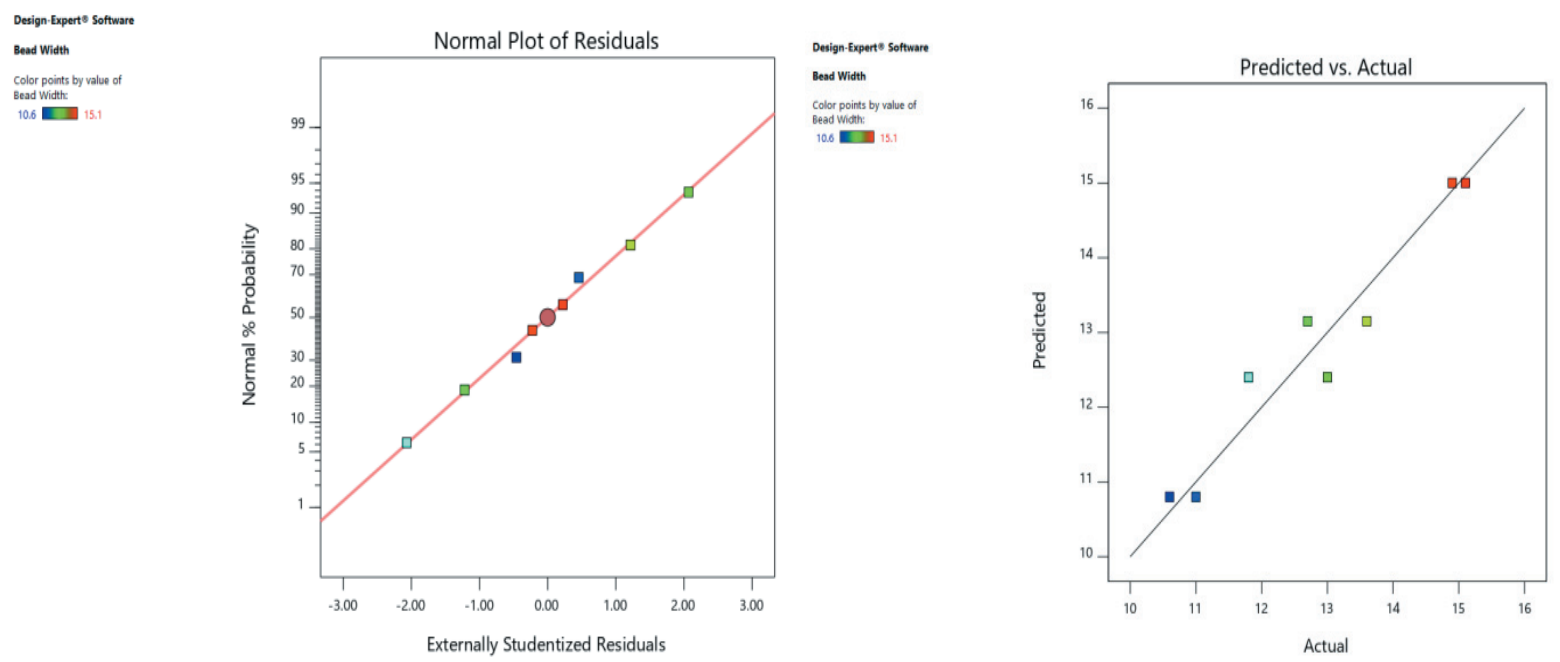

Figure 7. (a) Graph of residuals (b) Graph of predicted vs actual bead width

Equations to forecast the behaviour in coded form is shown as:

Bead Width $=12.8375+0.0625(\mathrm{~A})-0.8625(\mathrm{~B})-1.2375(\mathrm{~A} * \mathrm{~B})$

The graph of residuals along with graph of predicted vs actual bead width is given in Figure 7 (a) and (b) respectively. All the points on the graph are very near to the straight line which shows that there is very small variation in the predicted and actual values. Equation 2 provides the information of bead width of model in the coded form where $\mathrm{A}$ is voltage and $\mathrm{B}$ is travel speed.

\section{CONCLUSION}

In the present study, agglomerated flux for the SAW was designed and developed in the lab. The mechanical property such as hardness of welded joints, for developed flux was analysed. The experimental results were analysed and correlated with the help of standard data and modelling. On the basis of results the following conclusions were drawn.

From this study, it is resolved that the changes in of the voltage and travel speed interrupts the hardness of bead during submerged arc welding process. This will be helpful to achieve the desired hardness of the welded joint while designing the flux for the various applications. On the contrary, the hardness of the weld bead was greater than that of base metal. So, the speed travel becomes the major factor for the hardness control of the such joints.

The result of the study quantified that weld bead width was very close to the values of the developed agglomerated flux. Hence it is proved that width of weld bead can also controlled by travel speed. 


\section{REFERENCES}

Lewis, W. J.; Faulkner, G. E.; Rieppel, P. J., 1961, Flux and Filler -Wire Developments for Submerged -Arc Welding HY-80 Steel, Welding Journal, Vol.1, pp.337s-345s.

Butler, C. A.; Jackson, C. E., Welding Journal,1967, Submerged Arc Welding Characteristics of $\mathrm{CaO}-\mathrm{TiO}_{2}-\mathrm{SiO}_{2}$ System, pp.448s-455s.

Palm, J. H. Welding Journal, July 1972, How Fluxes Determine the Metallurgical Properties of Submerged Arc Welds, Welding research supplement,358s-360s

Paniagua, Ana. Ma.; Victor, M.; Saucedo, Marible, L., 2005, Journal of Materials Processing Technology, Vol.169, Influence of the Chemical Composition of Flux on the Microstructure and Tensile Properties of Submerged-arc Welds, pp.93-100.

Kanji lal, P.; Pal, T. K.; Majumdar, S. K., 2006, Journal of Materials Processing

Technology Vol.171, Combined Effect of Flux and Welding Parameters on Chemical Composition and Mechanical Properties of Submerged-arc Weld Metal, pp. 223-231.

Sharma, Abhay; Arora, Navneet; Mishra, Bhanu, K., 2008, Mathematical Modelling of Flux Consumption During Twin-wire Welding Int. J. Adv. Manuf Technology, pp.1114-1124

Kumar, Vinod, 2011, Modelling of Weld Bead Geometry and Shape Relationship in Submerged Arc Welding Using Developed Fluxes, Jordan Journal of Mechanical and Industrial Engineering, Vol.5, No. 5, pp. 461-470.

Gautam, Uma, 2017, Effect of Flux in Submerged Arc Welding- A Review. 4 International Journal of Advanced Engineering Research and Science. 44-46. 10.22161/ijaers.4.12.8.

Ajay Kumar, Hari Singh and Sachin Maheshwari, Dec 2012, Modelling and analysis by response surface methodology of hardness for submerged arc welded joints using developed agglomerated fluxes Indian journal of Engineering and Material Science, Vol.19, pp-379-385 